\title{
It's only love? Some pitfalls in emotionally related organ donation
}

Nikola Biller-Andorno and Henning Schauenburg University of Goettingen, Germany

\begin{abstract}
Transplanting organs from emotionally related donors has become a fairly routine procedure in many countries. However, donors have to be chosen carefully in order to avoid not just medically, but also morally, questionable outcomes. This paper draws attention to vulnerabilities that may affect the voluntariness of the donor's decision. Suggestions are made as to how to approach the evaluation and selection of potential donors.

(Fournal of Medical Ethics 2001;27:162-164)
\end{abstract}

Keywords: Living organ donation; emotionally related donors; vulnerable persons; clinical ethics

\section{Introduction}

The scarcity of organs for transplantation is a frequently deplored fact that has stimulated intense reflection on possible strategies to ameliorate this situation. ${ }^{1}$ One measure taken to alleviate the shortage is to accept not just genetically related, but emotionally related donors, ie not just parents and siblings, but also spouses or close friends. The German transplantation law, for example, in general allows donations to persons who obviously have a close personal relationship with the prospective recipient. ${ }^{2}$ The percentage of living kidney donations in Germany has risen from $4 \%$ of all kidney donations in 1994 to $15 \%$ in $1998 .^{3}$ In the US, the percentage of living kidney donations has gone up from an already remarkable $39 \%$ of all kidney donations in 1994 to $44 \%$ in $1998 .{ }^{4}$ However, there are voices in the medico-ethical and transplant community calling for further increases in living donation, demanding an active recruitment of emotionally related donors by transplant centres: "If the large potential contribution of emotionally related donors is ever to be realized, transplant centers must go beyond simply accepting such individuals and begin to actively encourage their participation".

The decision to accept somebody as a living organ donor is not to be taken lightly. Although the relatively low risk and the potential psychological benefits to the donor are frequently emphasised, the immediate as well as the-insufficiently known-long term risks of a unilateral nephrectomy in a perfectly healthy person cannot be called minimal or negligible. ${ }^{6} 7$ The risks involved in donating a partial liver, which is also practised with increasing frequency, are still higher. Therefore, evaluation of potential donors has to be a careful process. This becomes particularly important if the person offering to donate belongs to the group of people who have been characterised as "especially vulnerable". In the context of research on human subjects, this group has been singled out as persons who are not legally incompetent but "can be urged and persuaded to consent to research without really understanding its impact on their lives and especially on those who care for them" ${ }^{8}$ In living organ donation there is an analogous group of formally competent persons whose decision making capacity is compromised for different reasons, be it a dependent personality, social pressure, the cultural context or other circumstances. The following four case scenarios illustrate where difficulties can arise.

\section{Case scenarios}

CASE A

A middle-aged man suffering from severe liver cirrhosis due to a chronic hepatitis B infection was encouraged by his physician to ask his 29 -year-old wife if she could not donate a partial liver for him. The couple are both of Turkish nationality. Whereas the man had spent most of his childhood and adult life in Germany, his wife came here only after her marriage eight years ago. She speaks hardly any German. So far, she has been very busy raising two small children and working for a living. Her husband receives a small pension, not having been able to work for many years because of his disease. During an exploratory talk with the couple in the hospital the husband translates for his wife. There is no translator available, as it was assumed that communication in German would be possible. The woman wears a shy and friendly smile throughout and repeatedly confirms her readiness to donate. Her understanding of the implications of the donation as well as the degree of voluntariness of her decision remain uncertain. The husband, when probed, expresses his ambivalence: he desperately wants to "pull through" for his family, especially his two small children, on the other hand, he would rather not put his wife at risk.

\section{CASE B}

A couple in their forties present themselves for a partial liver transplantation. The prospective donor, the wife, is German, the prospective recipient, is Italian. They live with their four children in Southern Italy. The husband has had a longstanding alcohol problem, and his liver condition has 
deteriorated over the years. Over the last few months he has fallen repeatedly into a liver coma and has had to be treated in hospital. His wife talks enthusiastically about the donation and exhibits a great degree of determination to go for this transplantation "at any cost, no matter what". She had to watch her first husband die from a heart disease at a young age, and she does not want to lose her second one. However, when she is talked to alone in a calm moment during the week-long physical inpatient evaluation, she complains about her husband's "macho attitude" and the important influence of the extended family, who "get involved in everything" and who have urged her to donate.

CASE C

A 35-year-old man volunteers to donate a kidney. $\mathrm{He}$ does not have any family relationship to the prospective recipient, a wealthy and successful retired manager in his late $60 \mathrm{~s}$. The motivation is a completely altruistic one, he claims. In the past he has already donated blood on several occasions, so why not donate a kidney now? About a year ago, a friend, who happened to know someone in need of a kidney, acted as a go-between. The prospective recipient has lost both kidneys and feels he cannot tolerate dialysis any longer. Everything in his life had gone so well, he states, and now dialysis is "taking over", leaving him dependent and out of control. A cadaveric organ is not likely to be available to him in the near future. He thinks it is wonderful that a young man like the prospective donor is willing to give him a kidney. Of course this young man would not "vanish from his life" after donation. Indeed, he has already become like a son to him and his wife. There are things he could do for him - no payment, as this would be against the law, but maybe some help with finding a better job And in fact, the prospective donor might need such help, having been in prison several times and now trying to build a life with his new girl friend. $\mathrm{He}$ claims to feel enormous respect and sympathy for the prospective recipient, who somehow reminds him of his father who died when he was seven. Hence, he argues, only good is going to result from this transplantation.

\section{CASE D}

Anne, a woman in her late thirties, was cured of a genetic liver disease by a cadaveric transplantation some months ago and is now doing very well. She has returned to her job and seems to be bursting with energy and self confidence. While she enjoys her increased quality of life, she sees her husband's brother suffering from the same disease, although in his case it is predominantly the kidneys that are affected. In addition he has a disease of his blood vessels, which renders his prognosis, as well as any operation, rather problematic. Also, he has severe problems on dialysis, with recurrent shunt blockages. His physician says he will not stand many more years waiting for a cadaveric organ. His wife cannot donate to him due to blood group incompatibility and he has refused the offers of his teenage children. In this situation Anne, who lives next door and is confronted daily with his suffering, decided to donate a kidney. Anne and her husband had decided not to have children in order to avoid the risk of passing on the disease. However, they have always been very close to the brother-in-law's family. The children played frequently in their house, and they used to spend vacations together. Being in good health now herself, Anne does not want to "sit and watch" her brother-in-law's misery.

\section{Some reflections on the case scenarios}

In theory, the decision whether someone is a suitable living organ donor seems a straightforward matter. Laws and professional guidelines list criteria such as legal majority, free and informed consent, lack of equivalent therapeutic alternatives, and absence of financial recompense. Although some cases are indeed fairly unproblematic, practice shows that it is not always quite so easy, especially when emotionally related donors are concerned. In fact, a considerable proportion of these cases require intense scrutiny and interdisciplinary discussion. An obvious precondition for an adequate evaluation and selection of donors is that particularly vulnerable individuals or problematic social constellations are recognised as such. The case scenarios provide some examples of such vulnerabilities: language or cultural barriers (case A), emotional pressure from family and possibly from a dominating partner (case B); existential or material needs (case C), and feelings of guilt or at least a heightened sense of responsibility (case D). Of course one could give many other examples, such as cognitive impairment or the lack of other means to secure the potential recipient's survival in countries with few health care resources. ${ }^{9}$

Once difficult cases have been identified, it is important to pay particular attention to procedural points in order to avoid undesirable and morally problematic outcomes. Overambitious or insensitive recruitment is one of the possible pitfalls in that regard. Actively encouraging a potential donor, be it directly or through the prospective recipient, is inappropriate when there is an important power imbalance between physician and patient. Thus, a departmental or house policy on how to "recruit" or approach potential donors can be helpful. Ideally a well-informed donor would identify him- or herself without any action on the part of the physician. Sometimes, however, people are simply not aware of the possibility of emotionally related organ donation. It may therefore be justifiable to inform a patient on the waiting list or his or her accompanying relatives or close friends of this option. However, this has to happen in a very open, non-directive way. Otherwise people might be pressured into something they feel they cannot reject.

Another source of problems is the evaluation procedure of potential donors. What practical steps should be taken here in order appropriately to address problematic situations like those described in the case scenarios above? First of all the procedure should be transparent, with clearly 
divided responsibilities. The transplant physician or transplant surgeon will probably have the first contact with the prospective donor-recipient couple, inform them about risks and benefits, and perform an initial evaluation.

Then, as a next step, independent expertise, such as a psychosocial consultation service, should be brought in. ${ }^{10}$ As the surgeon might have an understandable interest in helping the patient suffering from severe kidney or liver disease, it is important to get the opinion of a person without "vested interests". There should be sufficient time for an in-depth talk with the potential donor and recipient, together, as well as individually. An interpreter is indispensable in the case of even moderate language barriers. Several appointments might be necessary, if the decision is not yet clear or if the donor or recipient is still insufficiently informed about possible risks. The main points to address are the history of the offer to donate and the motivation, the psychosocial stability of both, and the awareness that the outcome might be worse than expected. The goal of the evaluation should also be stated clearly, so that the atmosphere is more like an open exchange than that of a trial or interrogation. In the end, the consultant should be able to state whether there are any increased risks from a psychosocial perspective, if the donor as well as the recipient is comfortable with the idea of a living organ donation, and whether the donor is competent to make such a decision.

Ultimately, on the basis of these recommendations and the physical findings the transplant surgeon will have to make the decision about whether to go ahead. It is important, at this, and at all stages, to make sure both donor and recipient understand they can withdraw anytime without specific reasons. In particular, the donor might appreciate a medical "alibi" for this purpose, if he or she otherwise would not dare to disappoint the recipient. However, the donor's and recipient's decision to go ahead with a transplant is not enough - only if there is a reasonable risk-benefit ratio can a surgeon justify putting a healthy person at risk in order to help another. It is this active role in the redistribution of health or at least health risks that legitimates what might otherwise be considered inappropriately intrusive, for example, judging the quality of personal relationships or questioning the motives of a seemingly altruistic act. Only an adequate selection of donors and recipients can prevent medical, psychosocial, and ethical complications after a living organ donation.

\section{Conclusion}

It is undoubtedly a good thing that medicine can realise somebody's wish to donate an organ to a sick loved one. It is also understandable that there is an interest in obtaining as many organs as possible for suffering patients. But it is also beyond question that the decision to accept a donor has to be clinically adequate and ethically responsible. ${ }^{11}$

\section{Acknowledgment}

The authors would like to thank Dr Donna Dickenson, Imperial College School of Medicine, London, for very helpful comments on a previous draft of this paper.

Nikola Biller-Andorno, $M D, P h D$, is Assistant Professor in the Department of Medical Ethics and History of Medicine, Centre of Psychosocial Medicine, University of Goettingen, Germany. Henning Schauenburg, MD, is Associate Professor in the Department of Psychosomatic Medicine and Psychotherapy, the University of Goettingen, Germany.

\section{References and notes}

1 Gridelli B, Remuzzi G. Strategies for making more organs available for transplantation. New England Fournal of Medicine 2000;343:404-10

2 Gesetz ueber die Spende, Entnahme und Uebertragung von Organen (Transplantationsgesetz). Bonn: Bundesministerium fuer $\mathrm{Ge}-$ sundheit, 1997: para 8.1: "Personen, die dem Spender in besonderer persönlicher Verbundenheit offenkundig nahestehen".

3 Smit H, Sasse R, Molzahn M, Schulin B. Organspende und Transplantation in Deutschland 1998. 4. Bericht der Deutschen Stiftung Organtransplantation. Neu-Isenburg: Deutsche Stiftung Organtransplantation, 1999.

4 United Network for Organ Sharing (UNOS). Transplant patient data source. http://www.unos.org, 1999.

5 Spital A. Do US transplant centers encourage emotionally related kidney donation? Transplantation 1996;61:374-7: 374 .

6 Nicholson ML, Bradley JA. Renal transplantation from living donors. British Medical fournal 1999;318:409-10.

7 Johnson EM, Remucal MJ, Gillingham KJ, Dahms RA, Najar-

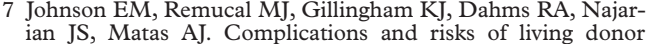
ian JS, Matas AJ. Complications and risks
nephrectomy. Transplantation 1997;64:1124-8.

nephrectomy. Transplantation $1997 ; 64: 1124-8$.
8 Thomasma DC. A model of community substituted consent for research on the vulnerable. Medicine, Health Care and Philosophy 2000; 3:47-57: 52 .

9 Biller-Andorno N, Agich GJ, Schauenburg H. Altruism, autonomy, and informed consent-the issue of living organ donation in borderline cases. Vth World Congress of Bioethics Abstractbook. London: International Association of Bioethics, 2000.

10 This could be a psychologist or psychiatrist. Ideally, a multidisciplinary team would be involved, including nursing staff, social workers, and maybe a primary care physicion who knows both the don, and the recipient well. This would be particularly the donor and the recipient well. This would be particularly (n) somatic medicine. In addition th level of the chambers of physicians, which exist in all the German states, that are supposed to ensure the voluntariness of the donor's decision and the absence of financial incentives

11 To that end, it would be useful to have an international collection of problematic cases of emotionally related organ donation, as a reference for colleagues in transplantation medicine or anybody else interested in the topic. These case reports would detail the medical and social context, the conflict, how it was solved, and if known, with what long term outcome. The authors would be willing to coordinate such an effort. For further information, please contact: Dr Nikola Biller-Andorno, Dept of Medical Ethics and History of Medicine, Humboldtallee 36, D-37073 Goettingen, Germany or by e-mail: nbiller@gwdg.de. 